\title{
Effect of Soil Burial on Silane Treated and Untreated Kenaf Fiber filled Linear Low-density Polyethylene/Polyvinyl Alcohol Composites
}

\author{
Ai Ling Pang, ${ }^{a}$ Agus Arsad, ${ }^{a, *}$ Mohsen Ahmadipour, ${ }^{\mathrm{b}}$ Hanafi Ismail, ${ }^{\mathrm{b}}$ and \\ Azhar Abu Bakar ${ }^{\mathrm{b}}$
}

\begin{abstract}
In recent decades, natural fibers have become widely used with petroleum based polymers such as polyethylene (PE) and polypropylene (PP) because of their light weight, lower cost, and inherent biodegradability. In the present work, linear low-density polyethylene/polyvinyl alcohol (LLDPE/PVOH) composites with untreated kenaf and silane-treated kenaf at filler loadings of 0,10 , and 40 phr were prepared via the melt mixing process. The soil burial test was used to evaluate the degradability of the composites for different durations (90 and $180 \mathrm{~d}$ ). The tensile properties, surface morphology, chemical composition, percentage of weight loss, and crystallinity of the composites before and after degradation were evaluated. With increased kenaf loading and soil burial duration, all the composites showed a decrease in tensile properties. This was further confirmed by the changes in surface morphology and chemical structure of the buried composites. The increase in weight loss percentage and crystallinity after soil burial indicated that the longer burial duration had increased the degradation of composites. Composites with silane-treated kenaf exhibited lower degradability than that of composites with untreated kenaf after being buried for 90 and $180 \mathrm{~d}$. This may be attributed to the improved adhesion of kenaf to the LLDPE/PVOH matrix via silane treatment.
\end{abstract}

Keywords: Silane treatment; Degradation; Soil burial; Kenaf fiber composites

Contact information: a: Institute for Oil and Gas, School of Chemical and Energy Engineering, Faculty of Engineering, Universiti Teknologi Malaysia, 81310 UTM Johor Bahru, Malaysia; b: School of Materials and Mineral Resources Engineering, Universiti Sains Malaysia (USM), Engineering Campus, 14300

Nibong Tebal, Penang, Malaysia; *Corresponding author:agus@utm.my

\section{INTRODUCTION}

Linear low-density polyethylene (LLDPE) is among the popular polyolefins that is frequently utilized for industrial packaging and applications such as plastic bags, wraps, containers, bottles, pipes, and cable covers (Nguyen et al. 2016; Guo 2020). However, LLDPE does not degrade easily in the natural environment and hence, research has shifted towards the use of biodegradable materials to partially or fully replace LLDPE (Ismail et al. 2009; Nguyen et al. 2016; Guo 2020). For instance, Ismail et al. (2009) successfully blended LLDPE with a synthetic biodegradable polymer, polyvinyl alcohol (PVOH), using the conventional processing method. Although PVOH may impart biodegradability to LLDPE, the cost of the product will increase because $\mathrm{PVOH}$ is an expensive raw material (Pang et al. 2017).

To make the LLDPE/PVOH matrix easier to degrade, natural fibers can be added to its composition. In addition to being economical and lightweight, natural fibers provide 
biodegradability to the polymer matrix (Moriana et al. 2010; Mitra 2014). One of the natural fibers that has gained popularity among researchers is kenaf fibers (John et al. 2010; Ramesh 2016). The massive growth on the development of kenaf fiber reinforced polymer composites can be attributed to the fact that kenaf has high specific mechanical properties, and it is lightweight, less costly, and able to degrade in different environments (Sapuan et al. 2013; Pang and Ismail 2014; Surip et al. 2016). Additionally, kenaf fiber based composites have been an attractive alternative particularly in industrialized applications such as automobile (interior panels, package trays, dashboard covering and headliners), food packaging (wrapping films, bags and containers), furniture (particle or fiber boards, composite chair and table), paper production, textile, etc. (Anandjiwala and Blouw 2007; Sreenivas et al. 2020). Moreover, kenaf fiber-based polymer composites have a good potential to substitute synthetic fiber based polymer composites such as glass-fibre polymer composite because they has comparable mechanical and physical properties to the latter (Kamal et al. 2014). However, the main drawback of kenaf fiber is its incompatibility with the hydrophobic polymer matrix, thereby leading to reduced adhesion and poor stress transfer (Pang et al. 2016). Numerous fiber-based treatments have been developed and published, with one of them being the silane treatment (Sobczak et al. 2013; Ahmad et al. 2015).

The degradation of fiber-based polymer composites relies upon several aspects such as the ability to degrade each component, fiber loading, and the interface's quality (Abdul Khalil et al. 2010). Many researchers have reported the introduction of high fiber loading generally increases the degradability of composites in the soil (Obasi and Onuegbu 2013; Rajesh et al. 2015; Yaacob et al. 2016). However, there are a few studies on the degradability of compatibilized polymer composites in the soil (Sam et al. 2011; Muniandy et al. 2012; Luthra et al. 2020). For instance, Muniandy et al. (2012) analyzed the degradability of 3-aminopropyltrimethoxysilane (AMEO)-treated and untreated rattan powder filled natural rubber composites in the soil. Results revealed that less degradation occurred in the AMEO-treated composites than the control composites because of the good rattan powder-matrix interaction and the AMEO protected and hindered it from degradation. Until now, the impact of different soil burial durations on the degradability properties of untreated and silane-treated kenaf filled LLDPE/PVOH composites have not been examined.

The highlight of this work was to comprehensively characterize the degradability of untreated and silane-treated kenaf filled LLDPE/PVOH composites in soil. The changes in the respective composites over time upon soil burial were assessed from the tensile properties, surface morphology, chemical structure, percentage of weight loss, and crystallinity. This work is essential to give basic knowledge of the degradation behavior of untreated and silane-treated kenaf filled LLDPE/PVOH composites in soil, which could be helpful for future applications that are involved in developing degradable fiber-polymer composites.

\section{EXPERIMENTAL}

\section{Materials and Methods}

The LLDPE and PVOH were purchased from PT Lotte Chemical Titan Nusantara (Banten, Indonesia) and Sigma-Aldrich (M) Sdn. Bhd. (Selangor, Malaysia). The density of LLDPE was $0.92 \mathrm{~g} / \mathrm{cm}^{3}$ with a melt flow rate of $1 \mathrm{~g} / 10 \mathrm{~min}$ at $190{ }^{\circ} \mathrm{C}$. The density and 
molecular weight of PVOH were $0.269 \mathrm{~g} / \mathrm{cm}^{3}$ and 89,000 to $98,000 \mathrm{~g} / \mathrm{mol}$, respectively. The LLDPE/PVOH had a ratio of $60: 40$ as the polymer matrix to prepare the composites. Kenaf was supplied from National Kenaf and Tobacco Board (LKTN), Kelantan, Malaysia. The 3-(trimethoxysilyl)propyl methacrylate (silane) was supplied by Sigma-Aldrich Sdn. Bhd. (Selangor, Malaysia) and was used to chemically treat the kenaf. Prior to the composites' preparation, kenaf was pre-treated with silane $5.0(\mathrm{wt} \%)$ as reported in previous work (Pang et al. 2016). Then, the kenaf was dried for $24 \mathrm{~h}$ in a vacuum oven at the temperature of $80{ }^{\circ} \mathrm{C}$ before being subjected to melt-mixing in an internal mixer (Model: R600/610; Thermo Haake, Karlsruhe, Germany) at a temperature and rotor speed of $150{ }^{\circ} \mathrm{C}$ and $50 \mathrm{rpm}$. The composites were then compression molded into a 1-mm-thick sheet with the use of an electrically heated hydraulic press (Model: KT-7014 A; GoTech Testing Machine, Taichung, Taiwan). The LLDPE/PVOH composites with $10 \mathrm{phr}$ and 40 phr of untreated kenaf and silane-treated kenaf were named 10UT, 10ST, 40UT, and 40ST, respectively.

\section{Characterizations}

The procedure of the soil burial test was conducted according to a previous report (Pang et al. 2017). The tensile testing was performed using a universal testing machine (Norwood, MA, USA) in accordance with ASTM D638-14 (2014). The surface morphology of composites after the soil burial was studied with a scanning electron microscope (SEM, Zeiss Supra-35VP; Carl Zeiss, Jena, Germany). A Fourier transform infrared spectroscopy (FTIR, Perkin Elmer System 2000 Spectrometer; Waltham, MA, USA) was used to study the structural changes of the soil buried composites. The percentage of weight loss of degraded composites was determined based on Eq. 1,

$$
\text { Weight Loss }(\%)=\left[\left(W_{0}-W_{1}\right) / W_{0}\right] \times 100
$$

where $W_{0}$ and $W_{l}$ are the weights $(\mathrm{g})$ of the samples before and after the soil burial test, respectively. The differential scanning calorimetry (DSC) measurements of the degraded composites were performed with a DSC 7 thermal analyzer (Pyris 6; PerkinElmer, Waltham, MA, USA) according to ASTM D3418-03 (2003). The crystallinity percentage was calculated based on Eq. 2,

$$
\text { Crystallinity }(\%)=\left[\Delta H_{\mathrm{f}} * /\left(W_{\mathrm{f}} \times \Delta H_{\mathrm{f}}{ }^{0}\right)\right] \times 100
$$

where $\Delta H_{\mathrm{f}}{ }^{0}$ and $\Delta H_{\mathrm{f}}{ }^{*}$ are the heat of fusion of LLDPE (290 J/g) (Ismail et al. 2009) and the experimental heat of fusion of the composites, respectively. Meanwhile, $W_{\mathrm{f}}$ refers to the weight fraction $(\mathrm{g})$ of LLDPE in the composites.

\section{RESULTS AND DISCUSSION}

\section{Tensile Properties}

Figure 1 shows the effect of different soil burial durations on the tensile strength of the LLDPE/PVOH composites with untreated and silane-treated kenaf. It was noted that the tensile strength decreased after soil burial of $90 \mathrm{~d}$ and $180 \mathrm{~d}$ for all the composites, respectively. Based on a previous study (Pang et al. 2017), the decline in tensile strength with increasing kenaf loading after soil burial was related to the weak interfacial adhesion between the untreated kenaf and LLDPE/PVOH that led to a higher moisture absorption from the soil. Figure 1 additionally shows that higher tensile strength was exhibited by the 
LLDPE/PVOH composites with silane-treated kenaf than that of composites with untreated kenaf, after 90 and $180 \mathrm{~d}$ of soil burial. This could be attributed to the enhancement in the interfacial adhesion between silane-treated kenaf and LLDPE/PVOH, which has been discovered in a previous study (Pang et al. 2016). Additionally, the moisture absorption of kenaf during soil burial could possibly be reduced after silane treatment. Consequently, the composites with silane-treated kenaf showed lower degradability during soil burial testing. Furthermore, it was observed in Fig. 1 that the tensile strength of all the composites decreased with increasing duration of soil burial. For instance, the tensile strength of LLDPE/PVOH composites with 10UT and 10ST decreased approximately $4.0 \%$ and $2.0 \%$ (after 90 days), and $8.8 \%$ and $4.6 \%$ (after 180 days), respectively. Similarly, decrement in tensile strength approximately $7.7 \%$ and $6.5 \%$ (after 90 days) and $11.8 \%$ and $11.5 \%$ (after 180 days) was shown by LLDPE/PVOH composites with 40UT and 40 ST, respectively. These results were expected because the composites experienced greater structural damage or degradation at longer soil burial durations.

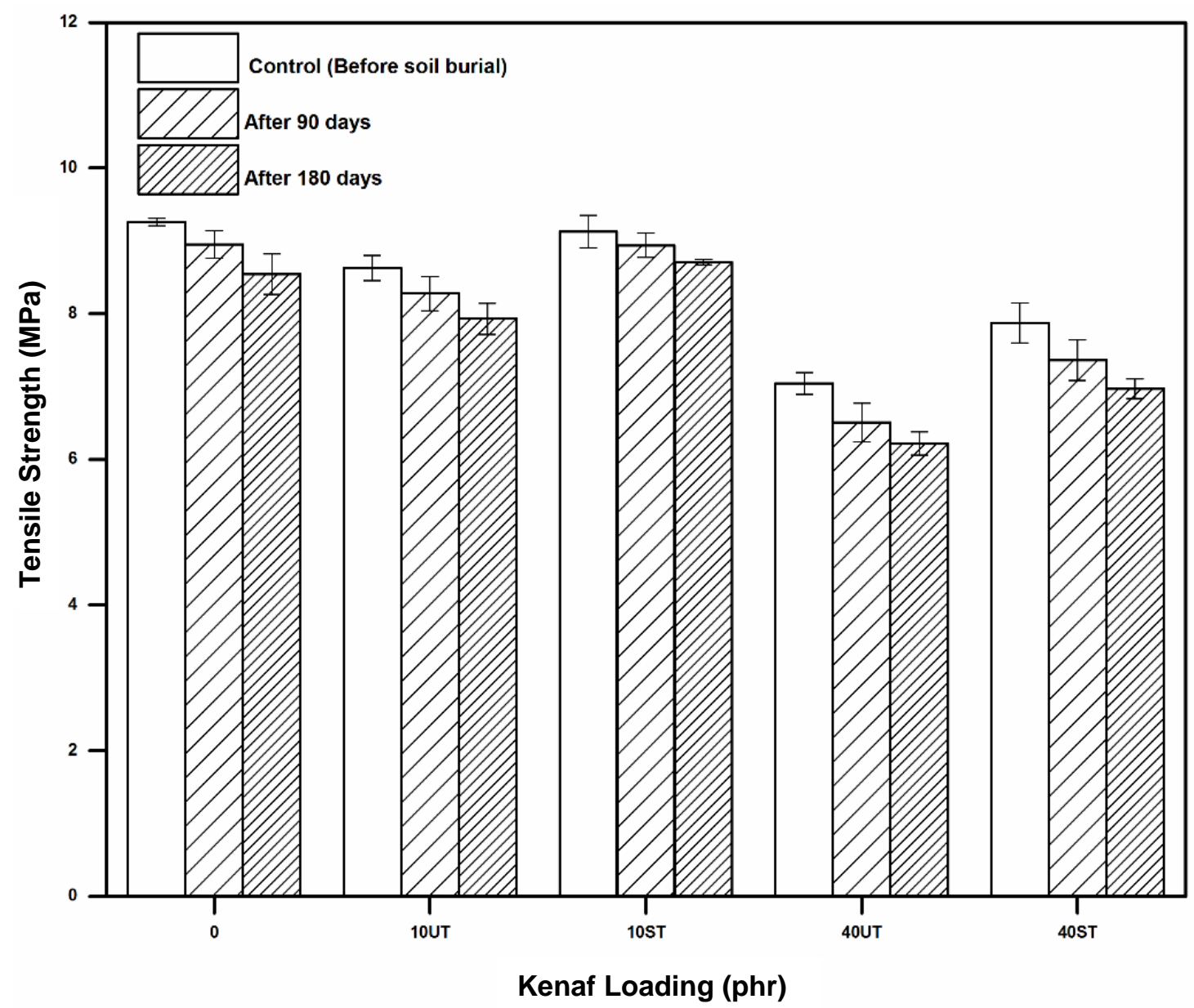

Fig. 1. Tensile strength of LLDPE/PVOH composites with untreated and silane-treated kenaf after $90 \mathrm{~d}$ and $180 \mathrm{~d}$ of soil burial

Based on the tensile results, the following degradation mechanism was proposed for a better understanding. During the soil burial, the kenaf fibers and the LLDPE/PVOH matrix were exposed to moisture absorption and microorganism attack. The microorganism attack on the polymer matrix resulted in surface erosion, thereby leading to the formation 
of pores or micro cracks on the surface as shown in the SEM micrograph in a later subsection (Figs. 5 and 6). Subsequently, the moisture can diffuse through the pores or micro cracks and attach to the hydrophilic groups of kenaf and $\mathrm{PVOH}$. As a result, the kenaf swelled after absorbing the moisture, generating stresses at the interface, and resulting in micro-cracking between the fibers and the matrix. This likely promoted more water to diffuse along with fiber-matrix interface and led to excessive moisture absorption. Eventually, solubilized components and byproducts of the kenaf started leaching out from the matrix, which can be attributed to excessive moisture absorption. These phenomena tend to degrade the tensile properties of the kenaf filled LLDPE/PVOH composites. However, the presence of improved interfacial adhesion between the silane-treated kenaf and the LLDPE/PVOH matrix can reduce the action of microorganisms and moisture that are present in the soil. A similar degradation mechanism was proposed by other researchers (Chan et al. 2019; Chee et al. 2019).

The effect of different soil burial duration on the elongation at break and tensile modulus of the LLDPE/PVOH composites with untreated and silane-treated kenaf is displayed in Figs. 2 and 3.

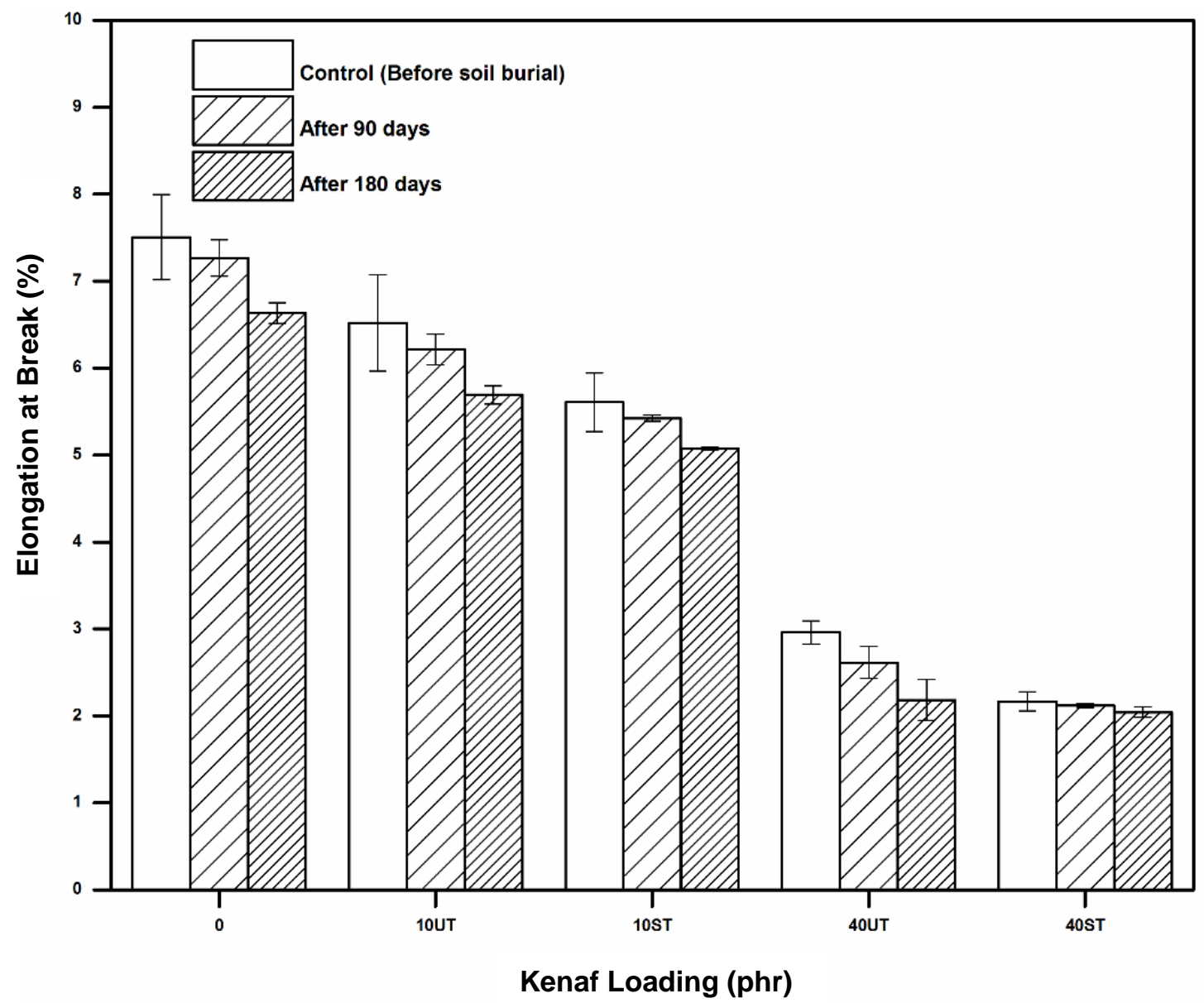

Fig. 2. Elongation at break of LLDPE/PVOH composites with untreated and silane-treated kenaf after $90 \mathrm{~d}$ and $180 \mathrm{~d}$ of soil burial 


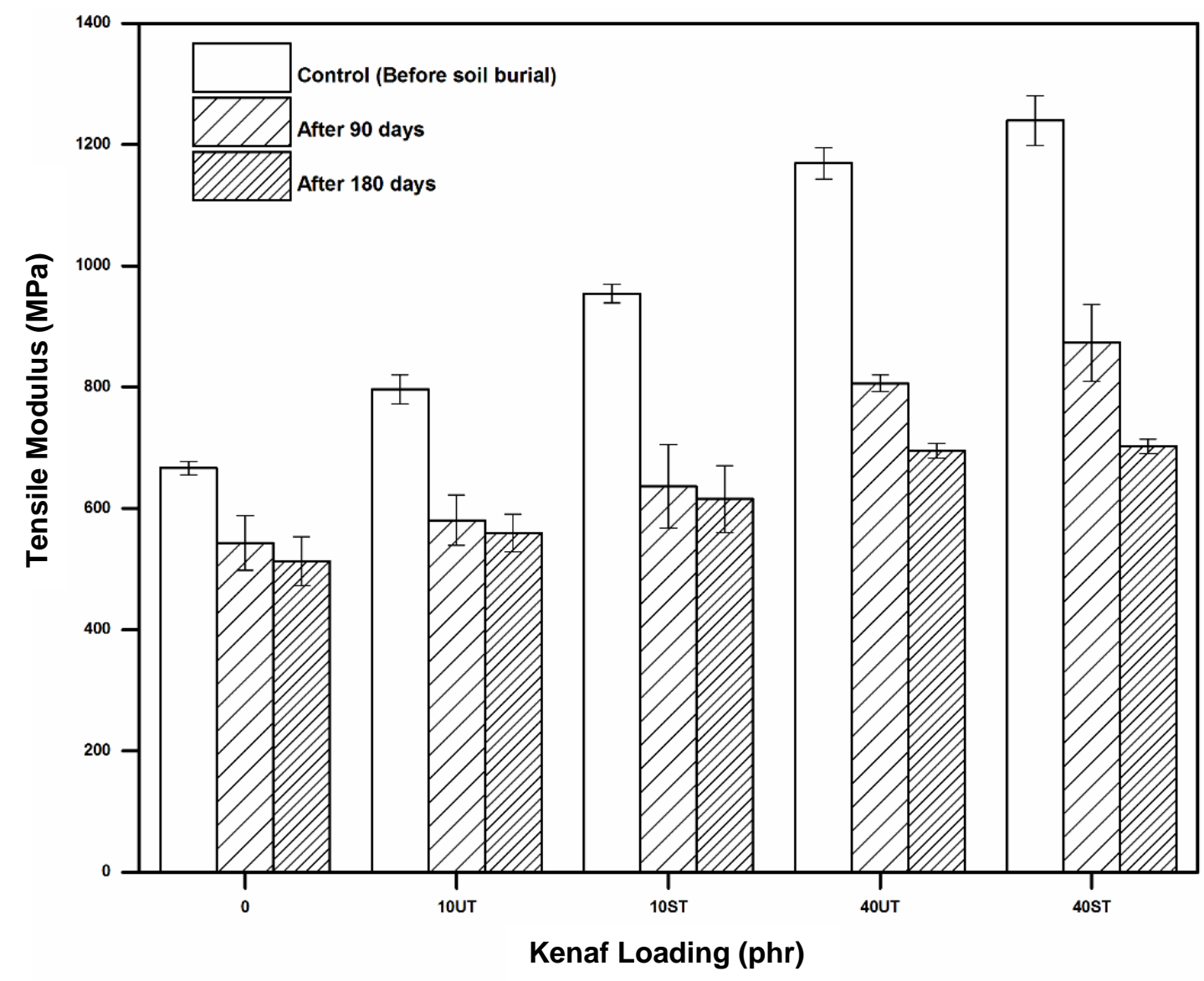

Fig. 3. Tensile modulus of LLDPE/PVOH composites with untreated and silane-treated kenaf after $90 \mathrm{~d}$ and $180 \mathrm{~d}$ of soil burial

Similar to the tensile strength trend (Fig. 1), elongation at break and tensile modulus of all the composites decreased after soil burial of 90 and $180 \mathrm{~d}$, respectively. The moisture absorption by kenaf from the soil during burial tended to result in leaching of kenaf from the composites, thereby leading to fiber-matrix debonding. Moreover, the leaching of kenaf tended to leave behind pores or voids on the composite surface. Consequently, the composites are vulnerable to the microorganism attack that may weaken the polymer structure or reduce the polymer chain length at prolonged burial time (Amer and Saeed 2015; Pang et al. 2017). Therefore, the flexibility and stiffness of the composites decreased as the burial prolonged. Nevertheless, LLDPE/PVOH composites with silane-treated kenaf exhibited lower elongation at break and higher tensile modulus in comparison to composites with untreated kenaf before and after soil burial exposure, respectively. This showed that the interface between silane-treated kenaf and the LLDPE/PVOH matrix was improved (Pang et al. 2016). Thereby the deterioration in mechanical properties was minimal (after soil burial) in comparison to the untreated kenaf filled LLDPE/PVOH composites.

\section{Morphological Study}

Figure 4 ( $a$ and $b$ ) shows SEM micrographs of untreated and silane-treated kenaf at magnification of 200x. From Fig. 4a, it can be seen there are many impure materials on the surface of untreated kenaf fibers. Silane treated kenaf fibre in Fig. $4 \mathrm{~b}$ illustrates a clean and 
smooth texture, with the impurities removed from its surface. Silane treatment is known for its efficiency in enhancing the kenaf fibre-matrix interfacial adhesion (Pang et al. 2016).
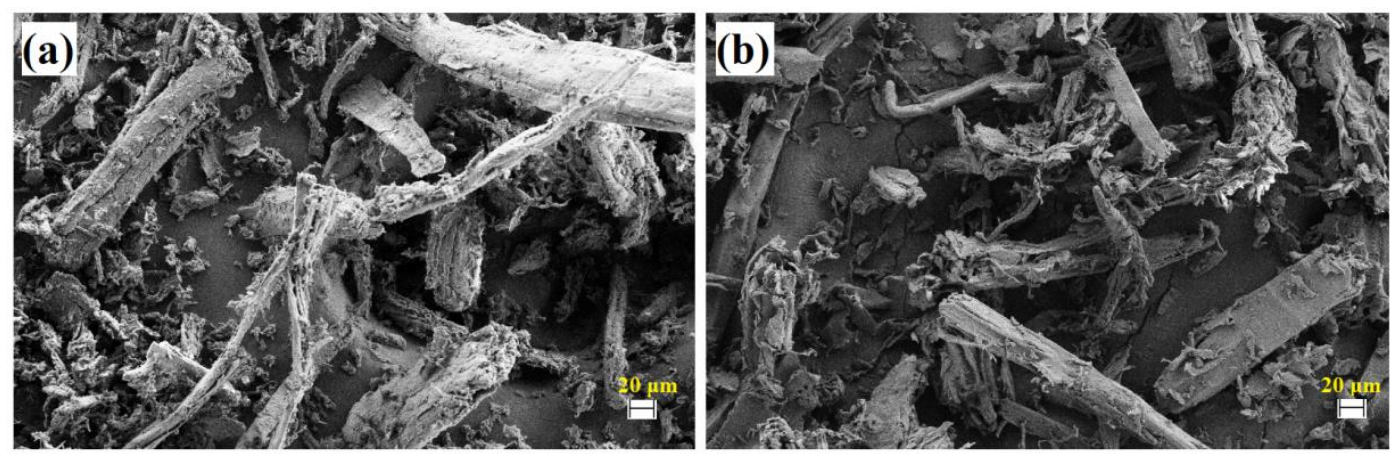

Fig. 4. SEM micrographs of kenaf fibers (a) UT; and (b) ST, at a magnification of 200x

The SEM micrographs of soil buried surfaces of LLDPE/PVOH composites with untreated and silane-treated kenaf are shown in Figs. 5 and 6, respectively. Figure 5 (a through d) illustrates the soil buried surfaces (after $90 \mathrm{~d}$ ) of LLDPE/PVOH composites with 10UT and 10ST.
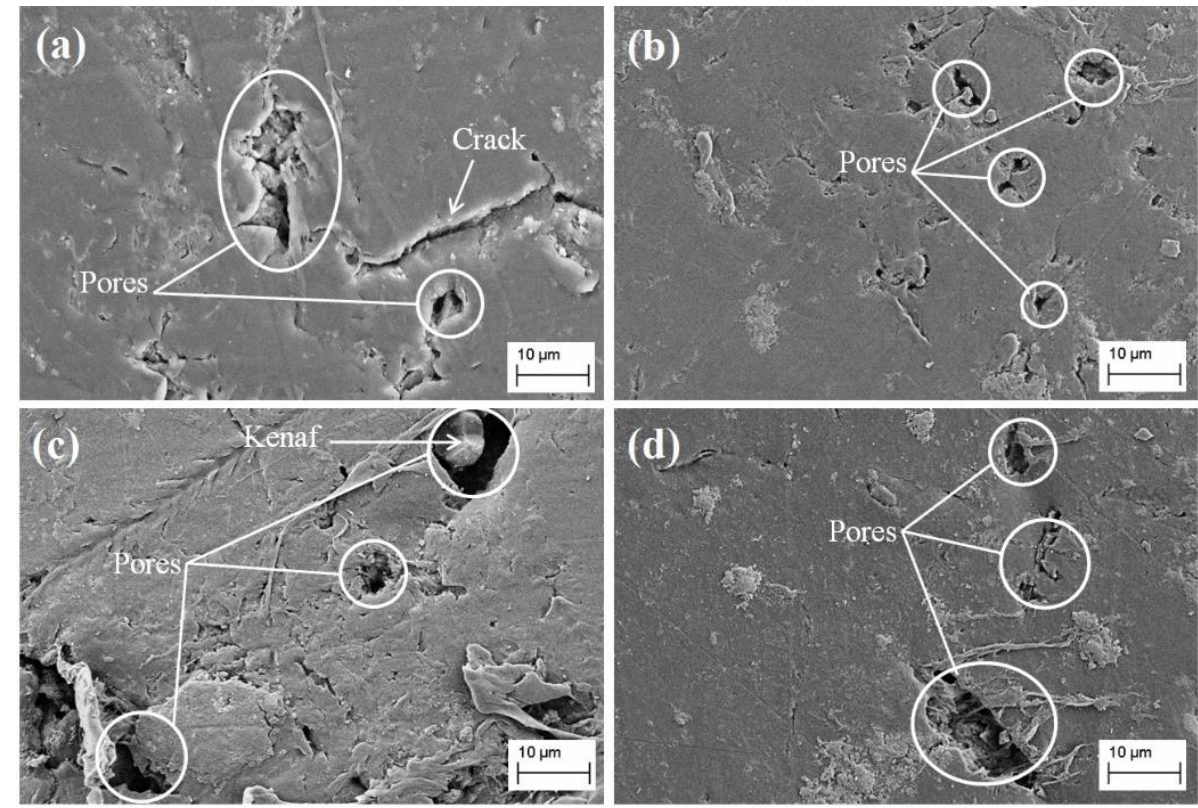

Fig. 5. SEM micrographs of LLDPE/PVOH composites with (a) 10UT (Pang et al. 2017); (b) 10ST; (c) 40UT (Pang et al. 2017); and (d) 40ST, after $90 \mathrm{~d}$ of soil burial exposure at a magnification of $1000 x$

Figure 5 (a) shows the presence of pores and cracks on the surface of LLDPE/PVOH/10UT composites. Figure 5 (c) shows the pores with bigger size on the surface of composites with higher kenaf loading (i.e., $40 \mathrm{phr}$ ). As discussed earlier, the microorganism attacks may lead to surface erosion and presence of pores or cracks on the surface of composites. Additionally, the leaching of kenaf from the composites could contribute to the formation of pores on the soil buried surface. This observation is in good agreement with the lower tensile strength values of LLDPE/PVOH/kenaf composites at 
higher kenaf loading, after the soil burial exposure. In contrast, the surfaces of LLDPE/PVOH composites with silane-treated kenaf after $90 \mathrm{~d}$ of soil burial (Fig. 5 (b, d)) were observed to have lesser and smaller pores than that of composites with untreated kenaf. This indicated better interfacial adhesion between the silane-treated kenaf and the matrix, thereby reducing the leaching of kenaf during soil burial.

Furthermore, with increasing burial time up to $180 \mathrm{~d}$, there were a higher number of surface pores and the size of pores were larger, as can be clearly seen in Fig. 6 (a-d). This is because the prolonged duration of soil burial is likely to increase the degradation of the composites (Sam et al. 2011). However, the surfaces of LLDPE/PVOH composites with silane-treated kenaf were observed to be less degraded in contrast to composites with untreated KNF, after $180 \mathrm{~d}$ of soil burial. This result is in agreement with the higher tensile strength of composites with silane-treated kenaf, as illustrated in Fig. 1.
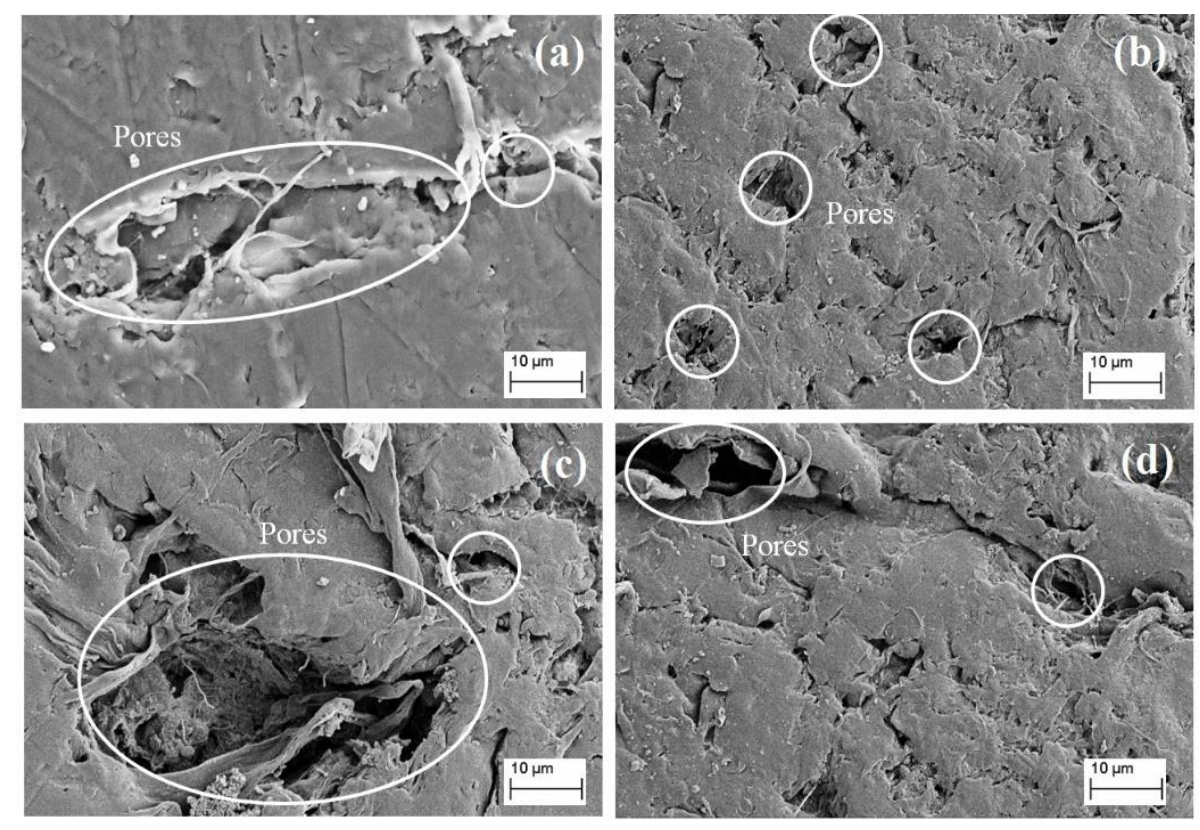

Fig. 6. SEM micrographs of LLDPE/PVOH composites with (a) 10UT (Pang et al. 2017); (b) 10ST; (c) 40UT (Pang et al. 2017); and (d) 40ST, after $180 \mathrm{~d}$ of soil burial exposure at a magnification of $1000 x$

\section{FTIR Analysis}

Figure 7 shows the FTIR spectra of LLDPE/PVOH composites with 40UT and 40ST after different durations of soil burial. The composites before soil burial were used as the control. It can be seen in Fig. 7 that both LLDPE/PVOH composites with 40UT and 40ST displayed a similar pattern in their respective FTIR spectra, except for the appearance of one additional peak at $989 \mathrm{~cm}^{-1}$ found in the LLDPE/PVOH/40ST composites. The peak at $989 \mathrm{~cm}^{-1}$ belonged to the Si-OH group (Rangel et al. 2010). The appearance of this peak indicated that silane induced better interaction between the kenaf and the LLDPE/PVOH matrix (Pang et al. 2016). Referring to Fig. 7, a small increment in the intensity of a peak within the range of 1750 to $1740 \mathrm{~cm}^{-1}$ (carbonyl group) was found after a prolonged soil burial time. This observation suggested that the degradation of composites in soil had occurred progressively with burial time (Sam et al. 2011; Yaacob et al. 2016). 
Furthermore, a considerably reduced absorption peak intensity of $\mathrm{O}-\mathrm{H}$ bending $\left(1645 \mathrm{~cm}^{-1}\right), \mathrm{C}-\mathrm{O}$ and C-O-C stretching (1100 to $\left.1056 \mathrm{~cm}^{-1}\right)$, C-O stretching $\left(838 \mathrm{~cm}^{-1}\right)$, and $\mathrm{C}-\mathrm{H}$ and $-\mathrm{CH}_{2}$ stretching $\left(719 \mathrm{~cm}^{-1}\right)$ were observed after $90 \mathrm{~d}$ and $180 \mathrm{~d}$ of soil burial. All of these peaks belong to the kenaf (Pang et al. 2017). This indicated that the kenaf was leached out and removed from the composites during soil burial. This finding was confirmed by the presence of pores or cavities as shown in Figs. 5 and 6.

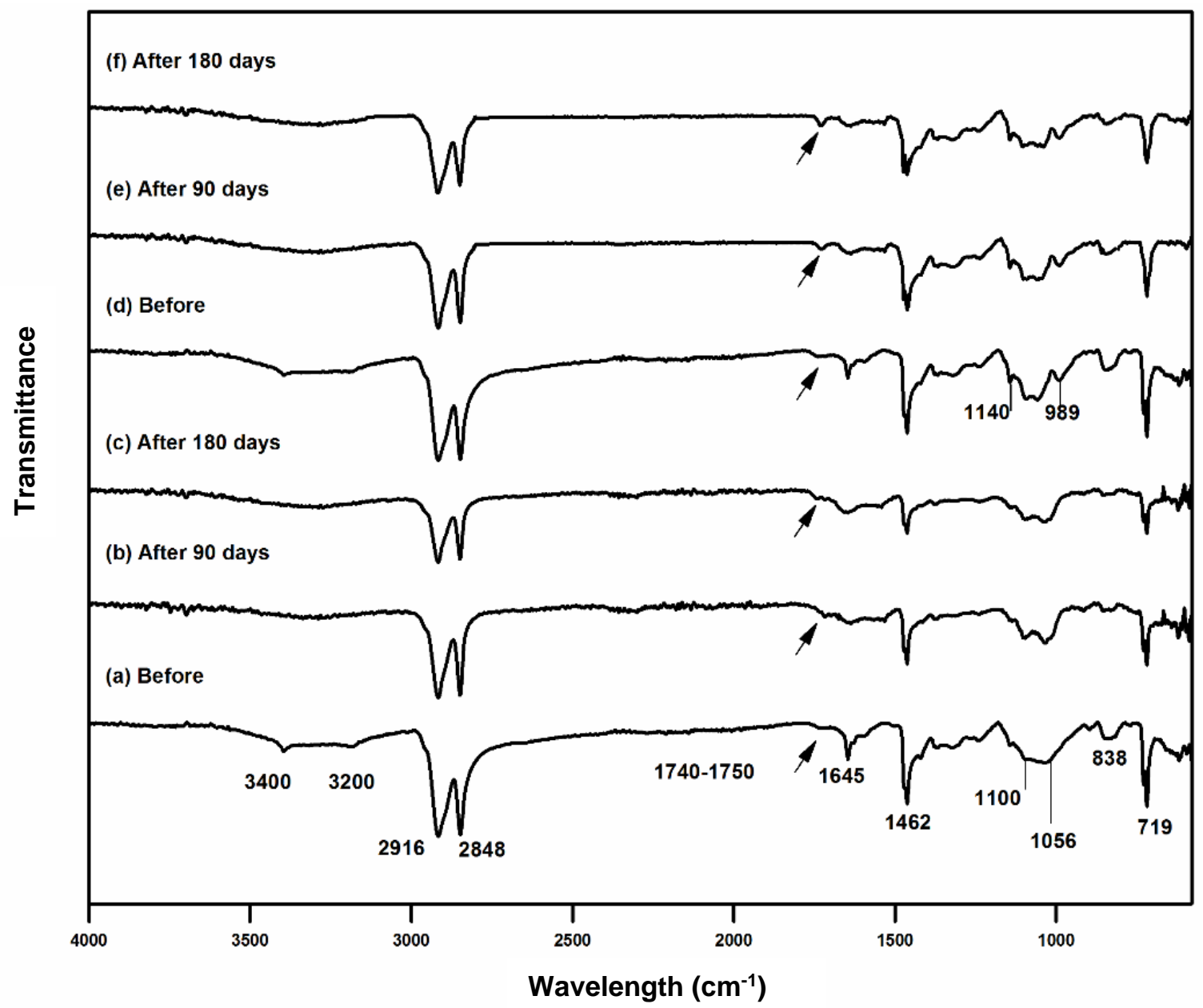

Fig. 7. FTIR spectra of LLDPE/PVOH composites with (a through c) 40UT; and (d through f) 40ST, before, and after $90 \mathrm{~d}$ and $180 \mathrm{~d}$ of soil burial, respectively

\section{Weight Loss}

During the soil burial exposure, biodegradation can happen due to moisture and microorganism attacks, resulting in weight losses of the material (Reddy et al. 2016; Chee et al. 2019). To observe the changes of the LLDPE/PVOH composites with untreated and silane-treated kenaf after soil burial, the percentage weight loss was evaluated, and the results are presented in Table 1. Referring to Table 1, LLDPE/PVOH exhibited a small weight loss percentage of approximately $0.21 \%$ and $0.98 \%$ after being buried for $90 \mathrm{~d}$ and $180 \mathrm{~d}$, respectively. This weight loss was attributed to the leaching of PVOH resulting from the moisture absorption from the soil. An apparent increase in the weight loss percentage was found in composites with the highest kenaf loading (i.e., $40 \mathrm{phr}$ ), after soil burial of $90 \mathrm{~d}$ and $180 \mathrm{~d}$. Generally, composites with higher kenaf loading led to higher moisture 
absorption from the soil during the burial, and this was likely to contribute to the degradation of the composites (Amer and Saeed 2015; Pang et al. 2017). These results are associated with the lower tensile strength values obtained in the previous section. However, at similar loading of kenaf and duration of soil burial, the LLDPE/PVOH composites with silane-treated kenaf showed a lower percentage of weight loss compared to composites with untreated kenaf. This corresponded to the enhanced adhesion of the fiber-matrix interface in the presence of silane and subsequently reduced the moisture absorption by the composites from the soil. This observation suggested that the composites with silanetreated kenaf exhibited fairly good tensile properties after soil burial.

Table 1. Percentage Weight Loss of LLDPE/PVOH Composites with Untreated and Silane-treated Kenaf After Different Durations of Soil Burial Exposure

\begin{tabular}{|c|c|c|c|c|}
\hline \multirow{2}{*}{$\begin{array}{c}\text { Kenaf } \\
\text { Loading } \\
\text { (phr) }\end{array}$} & \multicolumn{4}{|c|}{ Weight Loss (\%) } \\
\cline { 2 - 5 } & \multicolumn{4}{|c|}{ LLDPE/PVOH } \\
\cline { 2 - 5 } & UT & $180 \mathrm{~d}$ & $90 \mathrm{~d}$ & \multicolumn{2}{c|}{ ST } \\
\hline 0 & $90 \mathrm{~d}$ & 0.98 & - & - \\
\hline 10 & 0.21 & 2.32 & 0.49 & 10.99 \\
\hline 40 & 0.72 & 11.86 & 4.53 & $\mathrm{~d}$ \\
\hline
\end{tabular}

Furthermore, the percentage of weight loss increased with the duration of soil burial for both LLDPE/PVOH composites with untreated and silane-treated kenaf. After $90 \mathrm{~d}$ of soil burial, the increment of weight loss was approximately $1.60 \%$ and $7.02 \%$ for LLDPE/PVOH composites with 10UT and 40UT, respectively. These results were higher than that of LLDPE/PVOH composites with 10ST and 40ST (1.53\% and 6.46\%), respectively. This result was in good agreement with the deterioration in tensile properties after buried for $180 \mathrm{~d}$, which was discussed in the previous section.

\section{DSC Analysis}

The DSC results of untreated and silane-treated kenaf filled LLDPE/PVOH composites after different soil burial durations are summarized in Table 2. The reason for the decrease in the crystallinity $\left(X_{\mathrm{c}}\right)$ with increasing kenaf loading has been reported in the authors' previous study (Pang et al. 2017). Based on Table 2, the melting temperature $\left(T_{\mathrm{m}}\right)$ of the composites was observed in the range of 125.0 to $126.2{ }^{\circ} \mathrm{C}$, before and after soil burial. The small changes in $T_{\mathrm{m}}$ indicated that minimal changes had been initiated by the microorganism attacks on the matrix part of the composites (Luthra et al. 2020). Moreover, the crystallization temperature $\left(T_{\mathrm{c}}\right)$ and heat of fusion $\left(H^{*}\right)$ for both LLDPE/PVOH composites with untreated and silane-treated kenaf increased as the soil burial test prolonged. During the soil burial test, the amorphous region of a polymer was more vulnerable to microorganism attacks and hydrolysis in comparison to the crystalline region (Roy et al. 2015; Nguyen et al. 2016; Lv et al. 2018). The increase in $T_{\mathrm{c}}$ and $H^{*_{\mathrm{f}}}$ after soil burial corresponded to the degradation of kenaf (the amorphous portion) in the composites, which increased the crystalline portion. Hence, the overall crystallinity of the composites increased as burial progressed. This finding was similar to the results reported by several researchers, claiming that the crystallinity of the filled composites increased after soil burial (Yaacob et al. 2016; Huang et al. 2018; Luthra et al. 2020).

Nevertheless, at a fixed burial time, LLDPE/PVOH composites with 10ST and 40ST exhibited lower crystallinity than that of LLDPE/PVOH composites with 10UT and 
40UT, respectively. This can be explained by the action of the microorganisms and water from the soil acting on the silane-treated kenaf, which is less favourable, resulting from the better interfacial adhesion between silane-treated kenaf and LLDPE/PVOH matrix. Therefore, the degradability of LLDPE/PVOH composites with 10ST and 40ST in soil was lower in comparison to LLDPE/PVOH composites with 10UT and 40UT, respectively.

Table 2. DSC Results of LLDPE/PVOH Composites with Untreated and Silanetreated Kenaf After Different Durations of Soil Burial Exposure

\begin{tabular}{|c|c|c|c|c|c|c|c|c|c|c|c|c|}
\hline \multirow{2}{*}{ Sample } & \multicolumn{3}{|c|}{$\begin{array}{c}T_{\mathrm{m}} \\
\left({ }^{\circ} \mathrm{C}\right)\end{array}$} & \multicolumn{3}{|c|}{$\begin{array}{c}T_{\mathrm{c}} \\
\left({ }^{\circ} \mathrm{C}\right)\end{array}$} & \multicolumn{3}{|c|}{$\begin{array}{c}H_{f} \\
(\mathrm{~J} / \mathrm{g})\end{array}$} & \multicolumn{3}{|c|}{$\begin{array}{c}\text { Crystallinity, } X_{c} \\
(\%)\end{array}$} \\
\hline & $0 \mathrm{~d}$ & $90 \mathrm{~d}$ & $180 d$ & $0 d$ & $90 \mathrm{~d}$ & $180 d$ & $0 d$ & $90 \mathrm{~d}$ & $180 d$ & $0 d$ & $90 d$ & $180 d$ \\
\hline $\begin{array}{l}\text { LLDPE/ } \\
\text { PVOH }\end{array}$ & $\begin{array}{c}126 . \\
2\end{array}$ & 125.5 & 125.4 & 106.2 & 107.1 & 107.5 & 29.1 & 41.1 & 42.2 & 16.7 & 23.6 & 24.3 \\
\hline $\begin{array}{c}\text { LLDPE/ } \\
\text { PVOH/1 } \\
\text { OUT }\end{array}$ & $\begin{array}{c}125 . \\
8\end{array}$ & 125.7 & 125.1 & 106.9 & 107.0 & 107.3 & 25.3 & 28.4 & 33.2 & 16.1 & 18.0 & 21.0 \\
\hline $\begin{array}{c}\text { LLDPE/ } \\
\text { PVOH/4 } \\
\text { OUT }\end{array}$ & $\begin{array}{c}125 . \\
0\end{array}$ & 125.5 & 125.1 & 106.9 & 106.9 & 107.0 & 17.3 & 17.9 & 24.8 & 13.8 & 14.4 & 19.9 \\
\hline $\begin{array}{c}\text { LLDPE/ } \\
\text { PVOH/1 } \\
\text { OST }\end{array}$ & $\begin{array}{c}125 . \\
9\end{array}$ & 126.1 & 126.1 & 106.4 & 106.7 & 106.7 & 21.7 & 23.4 & 28.6 & 13.9 & 14.9 & 18.2 \\
\hline $\begin{array}{c}\text { LLDPE/ } \\
\mathrm{PVOH} / 4 \\
\text { OST }\end{array}$ & $\begin{array}{c}125 . \\
4\end{array}$ & 125.4 & 125.1 & 106.9 & 106.9 & 107.0 & 12.7 & 13.0 & 21.8 & 10.1 & 10.4 & 17.4 \\
\hline
\end{tabular}

\section{CONCLUSIONS}

1. The degradability of linear low-density polyethylene/poly(vinyl alcohol) (LLDPE/ $\mathrm{PVOH})$ composites untreated and silane-treated was enhanced in the presence of higher kenaf loading and at longer soil burial durations. Nevertheless, composites with silanetreated kenaf demonstrated a lower degradability compared with composites with untreated kenaf.

2. The results showed that the tensile strength, elongation at break, and tensile modulus of all the composites decreased after soil burial exposure. However, composites with silane-treated kenaf exhibited higher tensile properties compared to composites with untreated kenaf after soil burial.

3. The deterioration in the tensile properties of the composites after soil burial was confirmed by the presence of pores and cracks on the surface morphology with the use of scanning electron microscopy (SEM).

4. The Fourier transform infrared (FTIR) spectrometry results confirmed the degradation of the composites occurred after soil burial exposure.

5. The percentage of weight loss and crystallinity of all the composites increased at higher kenaf loading and after a longer soil burial duration. However, the composites with 
silane-treated kenaf exhibited a lower percentage of weight loss and crystallinity than that of composites with untreated kenaf after soil burial.

\section{ACKNOWLEDGMENTS}

The authors would like to acknowledge the grant (Q.J130000.21A2.05E25) from Universiti Teknologi Malaysia.

\section{REFERENCES CITED}

Abdul Khalil, H. P. S., Bhat, I. H. B., and Sartika, M. Y. (2010). “Degradation, mechanophysical, and morphological properties of empty fruit bunch reinforced polyester composites," BioResources 5(4), 2278-2296.

Ahmad, F., Choi, H. S., and Park, M. K. (2015). "A review: Natural fiber composites selection in view of mechanical, light weight, and economic properties," Macromol. Mater. Eng. 300(1), 10-24. DOI: 10.1002/mame.201400089

Amer, Z. J. A., and Saeed, A. Q. (2015). "Soil burial degradation of polypropylene/starch blend," Int. J. Tech. Res. Appl. 3(1), 91-96.

Anandjiwala, R. D., and Blouw, S. (2007). "Composites from bast fibres-prospects and potential in the changing market environment," J. Nat. Fibers. 4(2), 91-109, DOI: 10.1300/J395v04n02_07

ASTM D638-14 (2014). "Standard test method for tensile properties of plastics," ASTM International, West Conshohocken, PA, USA.

ASTM D3418-03 (2003). "Standard test method for transition temperatures and enthalpies of fusion and crystallization of polymers by differential scanning calorimetry," ASTM International, West Conshohocken, PA, USA.

Chan, C. M., Vandi, L. J., Pratt, S., Halley, P., Richardson, D., Werker, A., and Laycock, B. (2019). "Insights into the biodegradation of PHA/wood composites: Micro- and macroscopic changes," Sustain. Mater. Technol. 21, e00099-e00110. DOI: 10.1016/j.susmat.2019.e00099

Chee, S. S., Jawaid, M., Sultan, M. T. H., Alothman, O. Y., and Abdullah, L. C. (2019). "Accelerated weathering and soil burial on colour, biodegradability and thermal properties of bamboo/kenaf/epoxy hybrid composites," Polym. Test. 79, Article ID 106054. DOI: 10.1016/j.polymertesting.2019.106054

Guo, G. (2020). "Density reduction behaviors and cell morphology in extrusion of LLDPE/wood fiber composites with physical and chemical blowing agents," J. Appl. Polym. Sci. 137(26), 48829-48836. DOI: 10.1002/app.48829

Huang, Z., Qian, L., Yin, Q., Yu, N., Liu, T., and Tian, D. (2018). "Biodegradability studies of poly(butylene succinate) composites filled with sugarcane rind fiber," Polym. Test. 66, 319-326. DOI: 10.1016/j.polymertesting.2018.02.003

Ismail, H., Ahmad, Z., Nordin, R., and Rashid, A. R. (2009). "Processibility and miscibility studies of uncompatibilized linear low density polyethylene/poly (vinyl alcohol) blends," Polym. Plast. Technol. Eng. 48(11), 1191-1197. DOI: 10.1080/03602550903147379

John, M. J., Bellmann, C., and Anandjiwala, R. D. (2010). "Kenaf-polypropylene composites: Effect of amphiphilic coupling agent on surface properties of fibers and 
composites," Carbohydr. Polym. 82(3), 549-554. DOI: 10.1016/j.carbpol.2010.05.015

Kamal, I. B., Thirmizir, M. Z., Beyer, G., Saad, M. J., Rashid, N. A. A., and Kadir, Y. A. (2014). "Kenaf for biocomposites: An overview," J. Sci. Technol. 6(2), 41-66.

Retrieved from: https://publisher.uthm.edu.my/ojs/index.php/JST/article/view/796

Luthra, P., Vimal, K. K., Goel, V., Singh, R., and Kapur, G. S. (2020). "Biodegradation studies of polypropylene/natural fiber composites," SN Appl. Sci. 2, Article number 512.

Lv, S., Zhang, Y., Gu, J., and Tan, H. (2018). "Soil burial-induced chemical and thermal changes in starch/poly (lactic acid) composites" Int. J. Biol. Macromol. 113, 338-344. DOI: 10.1016/j.ijbiomac.2018.02.139

Mitra, B. C. (2014). "Environment friendly composite materials: Biocomposites and green composites," Polym. Sci. Technol. 64(3), 244-261. DOI: 10.14429/dsj.64.7323

Moriana, R., Karlsson, S., and Ribes-Greus, A. (2010). "Assessing the influence of cotton fibers on the degradation in soil of a thermoplastic starch-based biopolymer," Polym. Compos. 31(12), 2102-2111. DOI: 10.1002/pc.21007

Muniandy, K., Ismail, H., and Othman, N. (2012). "Biodegradation, morphological, and FTIR study of rattan powder-filled natural rubber composites as a function of filler loading and a silane coupling agent," BioResources 7(1), 957-971.

Nguyen, D. M., Do, T. V. V., Grillet, A. C., Thuc, H. H., and Thuc, C. N. H. (2016). "Biodegradability of polymer film based on low density polyethylene and cassava starch," Int. Biodeterior. Biodegradation 115, 257-265. DOI: 10.1016/j.ibiod.2016.09.004

Obasi, H. C., and Onuegbu, G. C. (2013). "Biodegradability and mechanical properties of low density polyethylene/waste maize cob flour blends," Int. J. Appl. Sci. Eng. Res. 2(3), 233-240. DOI: 10.6088/ijaser.020300007

Pang, A. L., and Ismail, H. (2014). "Studies on properties of polypropylene/(waste tire dust)/kenaf (PP/WTD/KNF) composites with addition of phthalic anhydride (PA) as a function of KNF loading," J. Vinyl Addit. Technol. 20(3), 193-200. DOI: $10.1002 / \mathrm{vnl} .21365$

Pang, A. L., Ismail, H., and Abu Bakar, A. (2016). "Tensile properties, water resistance, and thermal properties of linear low-density polyethylene/polyvinyl alcohol/kenaf composites: effect of 3-(trimethoxysilyl)propyl methacrylate," BioResources 11(3), 5889-5904. DOI: 10.15376/biores.11.3.5889-5904

Pang, A. L., Ismail, H., and Abu Bakar, A. (2017). "Degradation of linear low-density polyethylene/polyvinyl alcohol/kenaf composites," Iran. Polym. J. 26(9), 703-709. DOI: $10.1007 / \mathrm{s} 13726-017-0555-8$

Rajesh, G., Ratna Prasad, A. V., and Gupta, A. V. S. S. K. S. (2015). "Mechanical and degradation properties of successive alkali treated completely biodegradable sisal fiber reinforced poly lactic acid composites," J. Reinf. Plast. Compos. 34(12), 951961. DOI: $10.1177 / 0731684415584784$

Ramesh, M. (2016). "Kenaf (Hibiscus cannabinus L.) fibre based bio-materials: A review on processing and properties," Prog. Mater. Sci. 78-79, 1-92. DOI:

10.1016/j.pmatsci.2015.11.001

Rangel, N., and Leal-Garcia, T. (2010). "Spectroscopy analysis of chemical modification of cellulose fibers," J. Mex. Chem. Soc. 54(4), 192-197.

Reddy, T. R. K., Kim, H. J., and Park, J. W. (2016). "Renewable biocomposites properties and their applications," in: Composites from Renewable and Sustainable Materials, M. Poletto (ed.), InTechOpen, Online. DOI: 10.5772/65475 
Roy, S. B., Shit, S. C., Sengupta, R. A., and Shukla, P. R. (2015). "Biodegradability studies of bio-composites of polypropylene reinforced by potato starch," Int. J. Inno. Res. Sci. Eng. Technol. 4(3), 1120-1130. DOI: 10.15680/IJIRSET.2015.0403066

Sam, S. T., Ismail, H., and Ahmad, Z. (2011). "Soil burial of polyethylene-g-(maleic anhydride) compatibilised LLDPE/soya powder blends," Polym. Plast. Technol. Eng. 50(8), 851-861. DOI: 10.1080/03602559.2011.551977

Sapuan, S. M., Pua, F. L., El-Shekeil, Y. A., and AL-Oqla, F. M. (2013). "Mechanical properties of soil buried kenaf fiber reinforced thermoplastic polyurethane composites," Mater. Des. 50, 467-470. DOI: 10.1016/j.matdes.2013.03.013

Sobczak, L., Brüggemann, O., and Putz, R. F. (2013). "Polyolefin composites with natural fibers and wood modification of the fiber/filler-matrix interaction," J. Appl. Polym. Sci. 127(1), 1-17. DOI: 10.1002/app.36935

Sreenivas, H. T., Krishnamurthy, N., and Arpitha, G. R. (2020). "Comprehensive review on light weight kenaf fiber for automobiles," International Journal of Lightweight Materials and Manufacture 3(4), 328-337. DOI: 10.1016/j.ijlmm.2020.05.003

Surip, S. N., Jaafar, W. N. R. W., Azmi, N. N., and Hassan, N. A. (2016). "Biodegradation properties of poly (lactic) acid reinforced by kenaf fibers," Acta Phys. Pol. A 129(4), 835-837. DOI: 10.12693/APhysPolA.129.835

Yaacob, N. D., Ismail, H., and Sam, S. T. (2016). "Soil burial of polylactic acid/paddy straw powder biocomposite," BioResources 11(1), 1255-1269. DOI: 10.15376/biores.11.1.1255-1269

Article submitted: August 3, 2020; Peer review completed: September 12, 2020; Revised version received and accepted: September 20, 2020; Published: September 25, 2020.

DOI: 10.15376/biores.15.4.8648-8661 